\title{
Preface: Vulnerability and resilience of freshwater and marine ecosystems
}

\section{3rd International Limnology and Oceanography Conference (JILO)}

\author{
Céline Bertrand · Evelyne Franquet - Ivan Dekeyser • \\ Christophe Piscart
}

Published online: 30 June 2016

(C) Springer International Publishing Switzerland 2016

The 3rd International Limnology and Oceanography Conference (JILO) was held at the Aix Marseille University, Marseille, France, from 21-23 May 2014 and it was co-organised by the French Limnological Association (AFL) and the Union of French Oceanographers. The conference was attended by scholars as well as scientists, students, stakeholders and manufacturers. 210 Participants came from 13 countries, France, Britain, Poland, Spain, Switzerland, Algeria, Burkina Faso, Cameroun, Cote d'Ivoire, Morocco,

Guest editors: Céline Bertrand, Evelyne Franquet, Ivan Dekeyser \& Christophe Piscart / Vulnerability and Resilience of Freshwater \& Marine Ecosystems

C. Bertrand $(\square) \cdot$ E. Franquet

Institut Méditerranéen de Biodiversité et d'Ecologie marine et continentale (IMBE), Aix Marseille Université, CNRS, IRD, Avignon Université, Avenue Escadrille Normandie Niemen, 13397 Marseille, France

e-mail: celine.bertrand@imbe.fr

I. Dekeyser

Union of French Oceanographers (UOF), Aix Marseille Université, OCEANOMED 2, Campus de Luminy,

Marseille, France

C. Piscart

French Limnological Association (AFL), Ecosystèmes, Biodiversité, Evolution (ECOBIO), CNRS, Université Rennes 1, 263 avenue du Général Leclerc, 35042 Rennes, France
South Africa, Tunisia, Brazil, and presented 39 oral and 61 poster communications.

The main ecological theme of this conference was the Vulnerability and resilience of freshwater and marine ecosystems. Vulnerability is a theoretical concept that is being considered more and more frequently by both researchers and stakeholders from a wide variety of disciplines in the global change context. Vulnerability to climate change can be defined as "the degree to which a system is susceptible to, or unable to cope with, adverse effects of climate change, including variability and extremes. It's a function of the character, magnitude, and rate of climate variation to which a system is exposed, its sensitivity, and its adaptive capacity" (IPCC, 2007). The concept of resilience is part of vulnerability and it can be compared with the ability to adapt to changes by exploiting instability phenomena, which implies the ability to cope and adapt without necessarily returning to its exact prior state. Studying the vulnerability and resilience of freshwater, brackish water and marine ecosystems implies to be simultaneously concerned with the following two issues: the limitation of water resources and the loss of the ecological function associated with these ecosystems such as changes in biodiversity. This conference was proposed to explore knowledge relating biodiversity to functioning of freshwater, brackish water and marine ecosystems in order to understand how this scientific approach of vulnerability and resilience can benefit planning and public decision-making. 
The papers of this special section result from this conference and provides a variety of ideas pertaining to vulnerability and integrating restoration and conservation. Thibaut et al. (2015) highlight the clear and present danger of extinction of Sargassum conundrum in the Mediterranean, even though it currently enjoys no protection status. The work of Boudouresque et al. (2015) presents a bibliographic review of the functioning of Posidonia meadows (Posidonia oceanica seagrass meadow), summarizing the services associated with the Mediterranean ecosystem, specifically its necromass, which is particularly vulnerable and plays an important role in stabilizing coastal erosion and fixing carbon. Pellan et al. (2015) show the impact of global warming on the ecological success of the invasive species Dikerogammarus villosus. Rocarpin et al. (2015) demonstrate the key role played by functional niche plants in temporary Mediterranean marshes, it could be useful in developing water management plans, or even planning for how to adapt to a changing environment. Muller et al. (2015) analyse the local effects of restoring riparian forests on the quality of highly eutrophic streams and their role for the resilience of aquatic systems.

This conference on Vulnerability and resilience of freshwater and marine ecosystems (http://jilo-2014. sciencesconf.org) was partially funded by ONEMA, EDF partners. Special thanks goes to all members of scientific and organizing committees, and especially Dominique Estival, Laurent Cavalli, Benjamin Oursel, and the communication and administrative teams of the Mediterranean Institute for Biodiversity and Ecology (IMBE, Aix Marseille University). We thank the referees who invested their time in preparing reviews for the manuscripts of this special issue. We would like to thank the editorial and publishing units of Springer for their assistance during the publication process.

\section{References}

Boudouresque, C. F., G. Pergent, C. Pergent-Martini, S. Ruitton, T. Thibaut \& M. Verlaque, 2015. The necromass of the Posidonia oceanica seagrass meadow: fate, role, ecosystem services and vulnerability. Hydrobiologia, this issue. doi:10.1007/s10750-015-2333-y.

IPCC, 2007. Climate change 2007: synthesis report. Contribution of working groups I, II and III to the fourth assessment report of the intergovernmental panel on climate change. IPCC, Geneva, Switzerland.

Muller, I., M. Delisle, M. Ollitrault \& I. Bernez, 2015. Responses of riparian plant communities and water quality after 8 years of passive ecological restoration using a BACI design. Hydrobiologia, this issue. doi:10.1007/ s10750-015-2349-3.

Pellan, L., V. Médoc, D. Renault, T. Spataro \& C. Piscart, 2015. Feeding choice and predation pressure of two invasive gammarids, Gammarus tigrinus and Dikerogammarus villosus, under increasing temperature. Hydrobiologia, this issue. doi:10.1007/s10750-015-2312-3.

Rocarpin, P., S. Gachet, K. Metzner \& A. Saatkamp, 2015. Moisture and soil parameters drive plant community assembly in Mediterranean temporary pools. Hydrobiologia, this issue. doi:10.1007/s10750-015-2604-7.

Thibaut, T., A. Blanfuné, M. Verlaque, C. F. Boudouresque \& S. Ruitton, 2015. The Sargassum conundrum: very rare, threatened or locally extinct in the NW Mediterranean and still lacking protection. Hydrobiologia, this issue. doi:10. 1007/s10750-015-2580-y. 